\title{
Characterization of nio-bczy as composite anode prepared by a one- step sol-gel method
}

\author{
Nafisah Osman, ${ }^{a, b},{ }^{*}$ Shazana Mohd Senari c ${ }^{c}$ Abdul Mutalib Md Jani ${ }^{d}$ \\ a Faculty of Applied Sciences, Universiti Teknologi MARA, 02600 Arau, Perlis, Malaysia \\ b Proton Conducting Fuel Cell Group, Universiti Teknologi MARA, 40450 Shah Alam, Selangor, Malaysia \\ c Faculty of Applied Sciences, Universiti Teknologi MARA, 40450 Shah Alam, Selangor, Malaysia \\ d Faculty of Applied Sciences, Universiti Teknologi MARA, 35400 Tapah Road, Perak, Malaysia \\ *Corresponding author: fisha@uitm.edu.my
}

\section{Article history}

Received 30 September 2019

Revised 22 December 2019

Accepted 21 January 2020

Published Online 17 August 2020

\begin{abstract}
A high polarization resistance $\left(R_{p}\right)$ at intermediate temperature $\left(500-800^{\circ} \mathrm{C}\right)$ operation has become one of the major challenges in the development of proton-conducting fuel cells (PCFCs). $R_{p}$ is the resistance of the cell that contributes by the electrodes parts which are anode and cathode as well as their interfacial components. The present study focused on the NiO-Ba( $\left.\mathrm{Ce}_{0.6} \mathrm{Zr}_{0.4}\right)_{0.9} \mathrm{Y}_{0.1} \mathrm{O}_{3-\delta}$ (NiO$\mathrm{BCZY)} \mathrm{composite} \mathrm{anode} \mathrm{and} \mathrm{its} \mathrm{interfacial} \mathrm{parts} \mathrm{where} \mathrm{the} \mathrm{oxidation} \mathrm{process} \mathrm{takes} \mathrm{place.} \mathrm{The} \mathrm{NiO-}$ BCZY with a ratio of 50:50 was prepared by a sol-gel method and characterized by X-Ray Diffractometer (XRD), Field Emission Scanning Electron Microscopy/Energy Dispersive X-ray (FESEM/EDX), and Electrochemical Impedance Spectroscopy (EIS). At calcination temperature of $1100^{\circ} \mathrm{C}, \mathrm{NiO}$ and $\mathrm{BCZY}$ oxides can preserve their phases to form composite anode as proven by XRD analysis. Morphology of the composite anode as observed by FESEM was spherical with particle size in the range of 30-70 nm. XRD analysis showed the formation of Ni-BCZY after undergoing reduction process under wet $\mathrm{H}_{2}: \mathrm{N}_{2}(10 \%: 90 \%)$. As confirmed by the EIS data, the increased conductivity of the composite anode in wet $\mathrm{H}_{2}: \mathrm{N}_{2}(10 \%: 90 \%)$ indicates that the $\mathrm{NiO}$ in the composite anode was reduced to Ni metal. The fabricated NiO-BCZY composite anode has shown a good potential to be a promising anode in PCFC application.
\end{abstract}

Keywords: Composite anode, sol-gel method, conductivity

(C) 2020 Penerbit UTM Press. All rights reserved

\section{INTRODUCTION}

High polarization resistance at intermediate temperature has become one of the major problems for the development of protonconducting fuel cells (PCFCs). One way to overcome the high polarization resistance is to use composite electrodes that can increase the triple-phase boundary (TPB) length (Chevallier, Zunic et al. 2009). Nickel cermet is commonly used as an anode for PCFCs application due to its excellent catalytic activity towards hydrogen oxidation at specific temperature, offers significant cost saving as well as it provides a conduction path for electrons. Generally, the use of proton-conducting ceramic in the composite anode offers the extension of the TPB length to the whole anode volume and as a result, the electrochemical reaction occurred at the electrolyte/electrode interface is extended. In addition, the thermal expansion coefficient of the anode to the ceramic electrolyte can be adjusted (Fabbri, Pergolesi et al. 2010).

Owing to the qualities of proton-conducting ceramic, acceptordoped $\mathrm{BaCeO}_{3}$ compounds have been considered as electrolytes for PCFC since they show low activation energy and high proton conductivity at intermediate temperatures. Unfortunately, the compounds have poor chemical stability in the presence of $\mathrm{CO}_{2}$ and water vapor at higher temperatures. To look for a compromise between chemical stability and proton conductivity, the most effective technique is the partial substitution of $\mathrm{Ce}$ with $\mathrm{Zr}$ in acceptor-doped $\mathrm{BaCeO}_{3}$. For example, yttrium doped barium cerate-zirconate (BCZY) reveals both adequate proton conductivity as well as sufficient thermal and chemical stability over a wide range of conditions significant to fuel cell operation (Zuo, Dorris et al. 2006, Zuo, Zha et al. 2006, Fabbri, D'Epifanio et al. 2008).

Despite growing interest received by the PCFCs system, more research has been conducted by tailoring the microstructure of the anode. A good dispersion of particles in the anode is required to improve cell performance. To the best of our knowledge, only a few methods have been investigated to prepare the anode powders based on protonic conductors which are mechanical mixing (Zuo, Dorris et al. 2006) and combustion method (Nasani, Ramasamy et al. 2014). The mechanical mixing method is very costly and leading to coarse and inhomogeneous powders while a pure crystalline phase of the anode cannot be easily obtained by combustion method (Chevallier, Zunic et al. 2009). By taking an account the effect of synthesizing method on the microstructure of the anode, several existing synthesizing methods need to be modified in preparing anode powder for a promising PCFC anode. 
Thus, in this work, the NiO-BCZY composite anode was prepared by a one-step sol-gel method and the characteristics of the composite anode were examined.

\section{EXPERIMENTAL}

A stoichiometric amount of $\mathrm{Ba}\left(\mathrm{NO}_{3}\right)_{2}$ (99\%, ACROS), $\mathrm{Ce}\left(\mathrm{NO}_{3}\right)_{3} .6 \mathrm{H}_{2} \mathrm{O} \quad\left(99.5 \%, \quad\right.$ ACROS), $\mathrm{Zr}\left(\mathrm{NO}_{3}\right)_{2} \mathrm{O} . \mathrm{xH}_{2} \mathrm{O} \quad(99.5 \%$, ACROS), $\mathrm{Y}\left(\mathrm{NO}_{3}\right)_{3} .5 \mathrm{H}_{2} \mathrm{O}\left(99.9 \%\right.$, Aldrich) and $\mathrm{Ni}\left(\mathrm{NO}_{3}\right)_{2} .6 \mathrm{H}_{2} \mathrm{O}(99 \%$, ACROS) were dissolved in purified water under stirring process. The citric acid, which acts as a complexing agent was then added to the solution with molar ratios of soluble metal ions:citric acid of 1:1.5. The $\mathrm{pH}$ of the solution was adjusted to around 7 by adding the $\mathrm{NH}_{4} \mathrm{OH}$. The resulting solution was slowly vaporized on a hot plate at $120^{\circ} \mathrm{C}$. The heating and stirring processes were controlled accordingly. The browning gas (known as NOx) was released throughout the process and a dark brown gel was obtained. The black flakes were produced when the gel was dried in a furnace at $325^{\circ}$. Then the obtained black flakes were calcined at $1100^{\circ} \mathrm{C}$ with the heating/cooling rate of $10^{\circ} \mathrm{C} \mathrm{min}{ }^{-1}$ for $6 \mathrm{~h}$ to form fine NiO-BCZY powders.

To prepare the NiO-BCZY composite anode pellet, the NiOBCZY composite anode powder was uniaxially pressed into a pellet under $365 \mathrm{MPa}$ for about 1-2 minutes. Then, the anode pellet was sintered at $1300^{\circ} \mathrm{C}$ for 3 hours in an air atmosphere. The pellet was reduced at $700^{\circ} \mathrm{C}$ under a constant flow of a mixture containing $10 \%$ of $\mathrm{H}_{2}$ in $\mathrm{Ni}$ gas. The composite anode pellet before and after reduction process was analyzed for its microstructure, phase verification as well as electrochemical studies.

The electrochemical performance of the composite anode pellet was measured by a lab-designed electrochemical system at a temperature ranging from $500-800^{\circ} \mathrm{C}$ in humidified $\mathrm{H}_{2}: \mathrm{N}_{2}(10 \%: 90 \%)$ and $\mathrm{N}_{2}$ environment. The electrochemical impedance of the cell was evaluated by ZIVE SP2 Electrochemical Workstation (ZIVELAB WonATech) connected to a personal computer. EIS was recorded at the applied frequency range of $0.1 \mathrm{mHz}$ to $1 \mathrm{MHz}$ with an $\mathrm{AC}$ amplitude range of $1 \mathrm{mV}$ to $10 \mathrm{mV}$. The obtained EIS curves were analyzed using ZMAN software.

\section{RESULTS AND DISCUSSION}

Fig. 1 reports the XRD pattern of the composite anode powder after calcined at $1100^{\circ} \mathrm{C}$ which showed the presence of $\mathrm{NiO}$ (JCPDS 78-0643) and BCZY phases (JCPDS 89-2485). The pronounce peaks of $\mathrm{NiO}$ can be indexed to their Miller index $(h k l)$ of (111), (200) and (220) plane while the pronounced peaks of BCZY can be indexed to (110), (111), (200), (211), (220), (310), and (222), respectively. Traces of $\mathrm{BaCO}_{3}$ also could be observed in the XRD pattern which were influenced by the high firing temperature and incomplete combustion of BCZY ceramic. According to Abdullah et al. (Abdullah, Osman et al. 2012), high temperature is needed to break the $\mathrm{BaCO}_{3}$ bond once it formed during the processing stage.

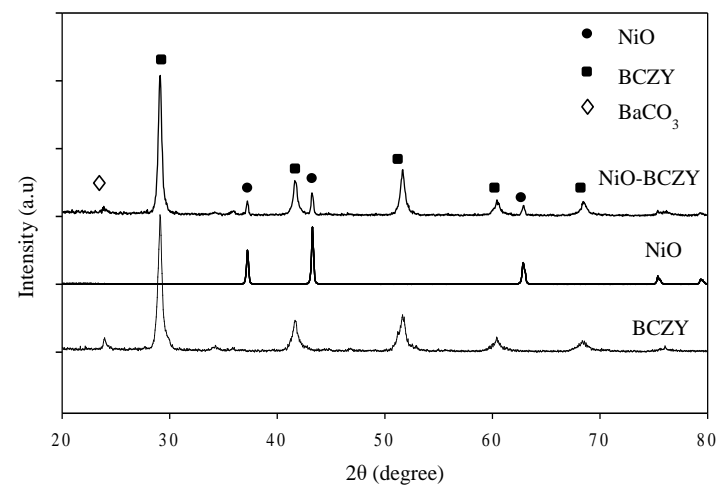

Fig. 1 XRD Patterns of NiO-BCZY Composite Anode After Calcined at $T=1100^{\circ} \mathrm{C}$
Fig. 2 presents the FESEM image of NiO-BCZY composite anode powder after calcined at $1100^{\circ} \mathrm{C}$ for $6 \mathrm{~h}$. The particle obtained was spherical in shape, size in the range of 30 to $70 \mathrm{~nm}$, and with less agglomerates due to the presence of citric acid as a chelating agent. This agent binds the metal ions to form metal complexes and hindered the formation of aggregates in the composite anode. The chelating agent could enrich the interaction among the metal species through homogeneous dispersion of the metal-chelate matrix as it can effectively preserve the molecular level mixing of metal ions in the precursor.

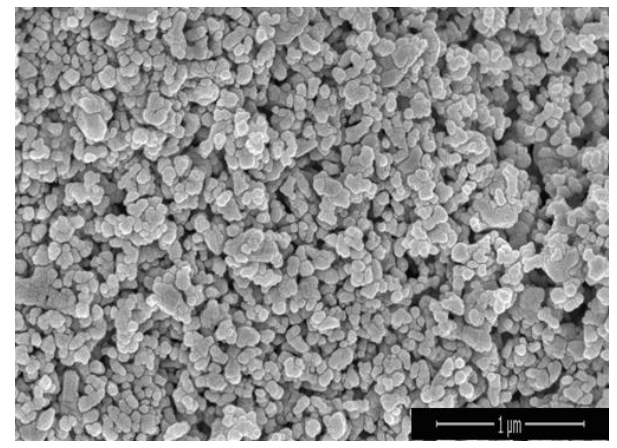

Fig. 2 Morphology of composite anode powder after calcined at $\mathrm{T}=1100^{\circ} \mathrm{C}$

In addition, the elemental composition of the prepared NiO-BCZY powder was investigated by EDX analysis and presented in Table 1. The percentage weight of each element obtained from EDX analysis was used to calculate the mole fraction. The elemental fraction of $\mathrm{Ba} / \mathrm{Ce} / \mathrm{Zr} / \mathrm{Y}$ obtained in the NiO-BCZY composite anode was close to the nominal fraction of NiO-BCZY. The result indicates that the onestep sol-gel method used for synthesizing NiO-BCZY does not alter the elemental composition of the final product.

Table 1 Elemental composition of NiO-BCZY powder.

\begin{tabular}{cccc}
\hline Element & $\begin{array}{c}\text { Elemental } \\
\text { Atomic } \\
\text { Percentage (\%) }\end{array}$ & $\begin{array}{c}\text { Calculate Mole } \\
\text { Fraction }\end{array}$ & $\begin{array}{c}\text { Nominal } \\
\text { Mole } \\
\text { Fraction }\end{array}$ \\
\hline $\mathrm{Ba}$ & 23.77 & 1.00 & 1.00 \\
$\mathrm{Ce}$ & 12.65 & 0.54 & 0.54 \\
$\mathrm{Zr}$ & 8.99 & 0.38 & 0.36 \\
$\mathrm{Y}$ & 1.47 & 0.06 & 0.10 \\
$\mathrm{Ni}$ & 17.78 & - & - \\
$\mathrm{O}$ & 16.86 & - & - \\
\hline
\end{tabular}

XRD analysis of the pellet before reduction confirmed the presence of the $\mathrm{NiO}$ and $\mathrm{BCZY}$ phases, while the existence of $\mathrm{Ni}$ metal (JCPDS 87-0712) and BCZY crystalline phases were detected after the reduction process as shown in Fig. 3. The pronounce peaks of $\mathrm{Ni}$ metal can be indexed to $(111)$ at $2 \theta=44.5^{\circ}$ and $(220)$ at $2 \theta=76.3^{\circ}$ as also observed by Chevallier et al. (Chevallier, Zunic et al. 2009).

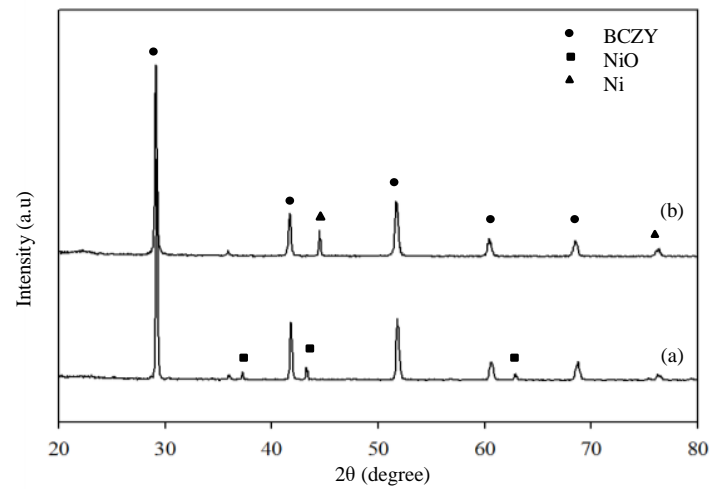

Fig. $3 \mathrm{X}$-ray Diffraction Pattern of (a) NiO-BCZY (before reduction) and (b) Ni-BCZY (after reduction) 
The electrical anode performance of the NiO-BCZY pellet was studied using impedance measurement in different environments. Fig. 5 shows the Nyquist impedance plots of the NiO-BCZY composite anode pellet under $\mathrm{N}_{2}$ gas and wet $10 \% \mathrm{H}_{2}: 90 \% \mathrm{~N}_{2}$ with temperature ranging from $400-700^{\circ} \mathrm{C}$. It could be observed that when the increasing of the temperature, the size of the EIS spectrum decreased. This observation shows that the involved reaction is thermally activated process in which the increasing temperature provides extra thermal energy to overcome the energy barrier in order for the process to occur.

Furthermore, there was also clearly seen the size of arcs for NiO$\mathrm{BCZY}$ in $10 \% \mathrm{H}_{2}: 90 \% \mathrm{~N}_{2}$ are smaller than the arcs for NiO-BCZY in $\mathrm{N}_{2}$ gas. The smaller arcs for $\mathrm{NiO}-\mathrm{BCZY}$ in $10 \% \mathrm{H}_{2}: 90 \% \mathrm{~N}_{2}$ revealed the low total resistance and high conductivity of the composite anode. The higher conductivity values of NiO-BCZY in wet $10 \% \mathrm{H}_{2}: 90 \% \mathrm{~N}_{2}$ are related to the microstructure of composite anode itself in the respective condition. In $\mathrm{N}_{2}$ condition, the particle size of $\mathrm{NiO}$ in the composite anode is bigger than the $\mathrm{Ni}$ in wet $10 \% \mathrm{H}_{2}: 90 \% \mathrm{~N}_{2}$ condition as the $\mathrm{NiO}$ started to reduce to metallic nickel. Hence, the length of the triple-phase boundary increased, enhancing the kinetics of hydrogen oxidation and indirectly increases the conductivity of the composite anode with smaller Ni particle size.
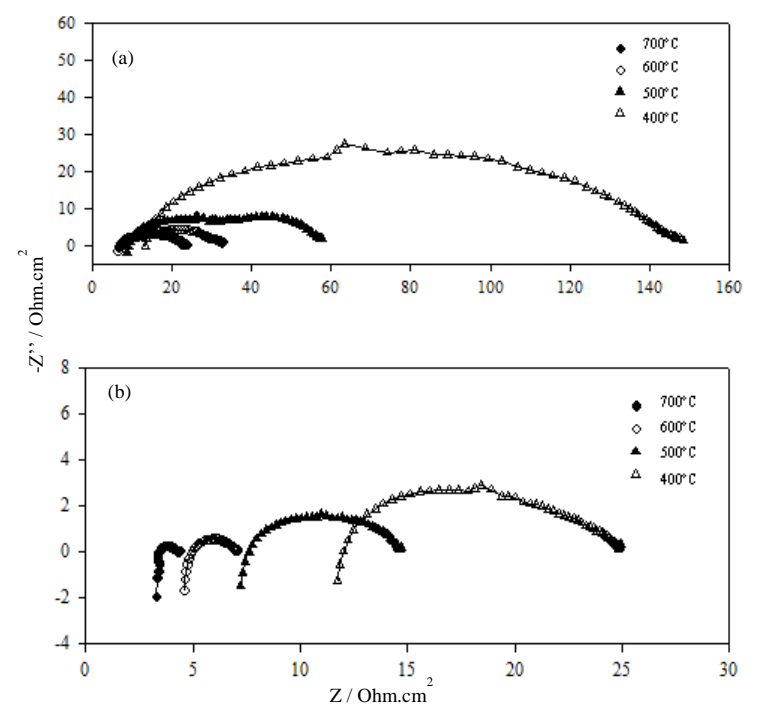

Fig. 5 The Nyquist Impedance Plots of NiO-BCZY Composite Anode Pellet Measured in (a) $\mathrm{N}_{2}$ gas and (b) wet $10 \% \mathrm{H}_{2}: 90 \% \mathrm{~N}_{2}$ at Temperature Range of $400-700^{\circ} \mathrm{C}$

\section{CONCLUSION}

A simple and low cost wet chemical method was developed to prepare NiO-BCZY composite anode powders for anode application in PCFCs. The XRD analysis of composite anode NiO-BCZY proved that the $\mathrm{NiO}$ and $\mathrm{BCZY}$ oxides could sustain their phases to form composite anode at a calcination temperature of $1100^{\circ} \mathrm{C}$. Morphology of the composite anode as observed by FESEM was spherical in shape with particle size in the range of 30-70 $\mathrm{nm}$. XRD analysis confirmed the formation of Ni-BCZY after undergoing the reduction process under wet $\mathrm{H}_{2}: \mathrm{N}_{2}$ (10\%:90\%). Electrochemical measurement on the NiO-BCZY pellets showed that the increasing conductivity in wet $\mathrm{H}_{2}: \mathrm{N}_{2}(10 \%: 90 \%)$ verified that the $\mathrm{NiO}$ in the composite anode was reduced to $\mathrm{Ni}$ metal and showing appropriate electrochemical features for promising anodes in PCFCs application.

\section{ACKNOWLEDGEMENT}

The authors thank the Minister of Higher Education (MOHE) for the Transdisciplinary Research Grant Scheme (600-IRMI/TRGS 5/3 (1/2016)-2) funding and Universiti Teknologi MARA for the facilities and support.

\section{REFERENCES}

Abdullah, N., N. Osman, S. Hasan, O. H. Hassan 2012. Chelating agents' role on thermal characteristics and phase formation of modified ceratezirconate via sol-gel synthesis route. Int. J. Electrochem. Sci 7: 9401-9409.

Chevallier, L., M. Zunic, V. Esposito, E. Di Bartolomeo, E. Traversa 2009. A wet-chemical route for the preparation of $\mathrm{Ni}-\mathrm{BaCe}_{0.9} \mathrm{Y}_{0.1} \mathrm{O}_{3-\delta}$ cermet anodes for IT-SOFCs. Solid State Ionics 180(9-10): 715-720.

Fabbri, E., A. D'Epifanio, E. Di Bartolomeo, S. Licoccia, E. Traversa 2008. Tailoring the chemical stability of $\mathrm{Ba}\left(\mathrm{Ce}_{0.8-\mathrm{x}} \mathrm{Zr}_{\mathrm{x}}\right) \mathrm{Y}_{0.2} \mathrm{O}_{3-\delta}$ protonic conductors for intermediate temperature solid oxide fuel cells (IT-SOFCs). Solid State Ionics 179(15-16): 558-564.

Fabbri, E., D. Pergolesi, E. Traversa 2010. Electrode materials: a challenge for the exploitation of protonic solid oxide fuel cells. Science and technology of advanced materials 11(4): 044301.

Nasani, N., D. Ramasamy, A. D. Brandão, A. A. Yaremchenko, D. P. Fagg 2014. The impact of porosity, $\mathrm{pH}_{2}$ and $\mathrm{pH}_{2} \mathrm{O}$ on the polarisation resistance of $\mathrm{Ni}-\mathrm{BaZr}_{0.85} \mathrm{Y}_{0.15} \mathrm{O}_{3-\delta}$ cermet anodes for Protonic Ceramic Fuel Cells (PCFCs). Int. J. of Hyd Energy 39(36): 21231-21241.

Zuo, C., S. Dorris, U. Balachandran, M. Liu 2006. Effect of Zr-doping on the chemical stability and hydrogen permeation of the $\mathrm{Ni}-\mathrm{BaCe}_{0.8} \mathrm{Y}_{0.2} \mathrm{O}_{3-\alpha}$ mixed protonic- electronic conductor. Chemistry of materials 18(19): 4647-4650.

Zuo, C., S. Zha, M. Liu, M. Hatano, M. Uchiyama 2006. $\mathrm{Ba}\left(\mathrm{Zr}_{0.1} \mathrm{Ce}_{0.7} \mathrm{Y}_{0.2}\right) \mathrm{O}_{3-\delta}$ as an electrolyte for low-temperature solid-oxide fuel cells. Adv. Mater. 18(24): 3318-3320. 